\title{
PELATIHAN DIGITAL MARKETING USAHA MIKRO, KECIL DAN MENENGAH (UMKM) DI KABUPATEN KARAWANG
}

\author{
Ade Andri Hendriadi ${ }^{\# 1}$, Betha Nurina Sari ${ }^{\# 2}$, Tesa Nur Padilah ${ }^{\# 3}$ \\ ${ }^{\#}$ Teknik Informatika, Universitas Singaperbangsa Karawang \\ Jl. HS Ronggowaluyo Telukjambe Timur, Karawang \\ ${ }^{1}$ hendriadi@unsika.ac.id \\ ${ }^{2}$ betha.nurinalstaff.unsika.ac.id \\ ${ }^{3}$ tesa.nurpadilahestaff.unsika.ac.id
}

\begin{abstract}
Abstrak
Internet sudah digunakan oleh berbagai kalangan masyarakat termasuk di dalamnya para pengusaha UMKM di daerah. Namun kurangnya wawasan dan edukasi bagi para pengusaha UMKM menyebabkan tidak optimalnya penggunaan internet dalam mendukung proses bisnis guna meningkatkan laba yang diraih oleh pelaku UMKM. Salah satu pemanfaatan internet dalam manajemen bisnis adalah digital marketing yang merupakan salah satu usaha untuk memasarkan atau mempromosikan sebuah produk melalui media internet agar bisa menjangkau konsumen maupun calon konsumen dengan cepat. Sehingga diharapkan manajemen usaha menjadi lebih optimal dan mendapatkan hasil yang maksimal.Produk unggulan dari UMKM Dapur MomieBaranie dengan BuTaRi (Bloeder Tape Durian) dan bolu terubuk serta UMKM dodol, minuman segar Cola van Java dan jus buah Kawista yang berbahan dasar buah Kawista yang merupakan buah khas Karawang, aktif di promosikan dengan mengangkat branding oleh - oleh khas Karawang melalui pengaplikasiandigital marketing. Akan tetapi belum optimalnya pengaplikasiandigital marketing yang dilakukan memotivasi usulan pelaksanaan pengabdian masyarakat dalam hal mengedukasi UMKM di Karawang terkait pengoptimalan digital marketing. Pelatihan digital marketing ini membantu UMKM untuk meningkatkan kemampuan para pengusaha UMKM dalam pemanfaatan digital marketing, ditandai dengan adanya kenaikan jumlah pesanan produk dari media online.
\end{abstract}

Kata Kunci-pelatihan, digital marketing, UMKM, Karawang

\section{Pendahuluan}

Digital marketing merupakan salah satu usaha untuk memasarkan atau mempromosikan sebuah produk melalui media internet agar bisa menjangkau konsumen maupun calon konsumen dengan cepat. Media internet yang sekarang ini populer digunakan untuk pemasaran produk antara lain, Facebook, Youtube, Instagram, dan media sosial yang lain. Manfaat yang didapatkan dengan digital marketing selain bisa menjangkau pasar yang lebih luas dan mengefektifkan biaya pemasaran, juga membuat ruang dan waktu pemasaran yang tidak terbatas. Selain itu, digital marketing bersifat real time sehingga pengusaha dapat langsung memperhatikan minat dan feed back dari pasar yang dituju, serta dapat memutuskan strategi penyesuaian terkait konten iklan untuk hasil yang lebih baik dengan lebih cepat.

BuceDarmawan, Konsultan Senior Proxsis IT, menyebutkan beberapa keuntungan penggunaan teknologi digital bagi UKM di Indonesia, yaitu:

1. Kenaikan pendapatan hingga $80 \%$;

2. Satu setengah kali lebih mungkin untuk meningkatkan kesempatan kerja;

3. 17 kali lebih mungkin untuk menjadi inovatif;

4. UKM yang lebih banyak menggunakan teknologi digital menjadi lebih kompetitif secara internasional
Internet sudah dikenal baik oleh semua kalangan masyarakat, termasuk para pengusaha UMKM di daerah, tetapi kurang optimal penggunaannya dalam mendukung manajemen usaha. Hal ini dikarenakan kurangnya wawasan dan edukasi kepada pengusaha UMKM terkait digital marketing. Padahal, dengan adanya digital marketing diharapkan manajemen usaha menjadi lebih optimal, sehingga pemasaran mendapatkan hasil yang maksimal. Hal inilah yang memotivasi usulan pelaksanaan pengabdian masyarakat dalam hal mengedukasi UMKM di Karawang terkait pengoptimalandigital marketing.

Manfaat teknologi yang dirasakan UMKM dan kenaikan pendapatan yang diharapkan oleh keterlibatan secara digital dan jumlah presentase kenaikan berdasarkan tingkat pertumbuhan dapat dilihat pada Gambar 1.1.

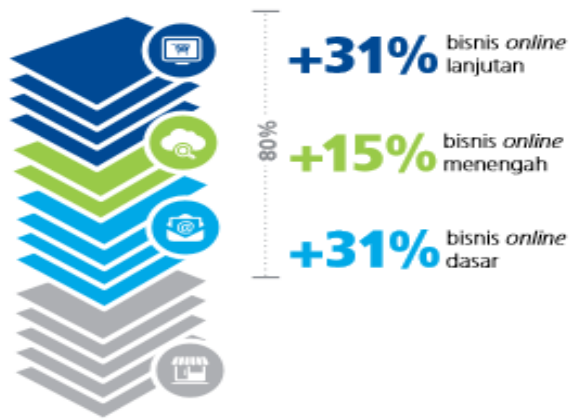




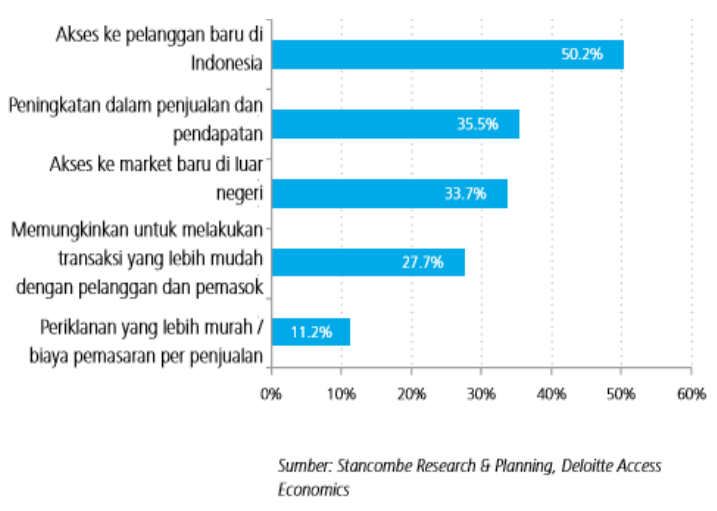

Gambar 1.1.Grafik Manfaat Teknologi untuk UMKM

Dari Gambar 1.1 dapat dilihat potensi yang sangat besar untuk digital marketing, ada penambahan $31 \%$ bisnis online lanjutan, penambahan $15 \%$ bisnis online menengah, dan penambangan $15 \%$ bisnis online dasar. Ketiga jenis penambahan tersebut hampir mencapai $80 \%$. Selain itu pada grafik di atas, informasi yang menarik mengenai akses ke pelanggan baru di Indonesia melebihi $50 \%$, adanya peningkatan dalam penjualan dan pendapatan setelah menggunakan teknologi sebesar 35\%, selain itu akses ke market/pasar baru di luar negeri mencapai $33,7 \%$. Teknologi masa kini bisa memungkinkan semua pelanggan dan penggiat UMKM melakukan transaksi yang lebih mudah, sebesar $27,2 \%$ dari informasi grafik di atas. Tidak hanya transaksi jual beli, urusan periklanan yang lebih murah bisa membuat biaya pemasaran per penjualan produk juga lebih murah, hal ini ditunjukkan dengan angka 11,2\% pada gambar 1.1 . Informasi inilah yang melatarbelakangi adanya ide dan gagasan untuk melaksanakan kegiatan pengabdian masyarakat yang bertemakan digital marketing.

Arief Rahmana [1] membahas tentang UKM menggunakan aplikasi jejaring sosial untuk mengenalkan produk, mendapatkan pelanggan baru dan loyalitasnya, meningkatkan penjualan, membangun kredibilitas, serta untuk mendapatkan respon umpan balik (feedback) dari pelanggan baik itu berupa saran, pendapat atau kritik mengenai produk usahanya.

Ada dua mitra UMKM sebagai model penerapan program edukasi terkait digital marketing, yaitu UMKM Dapur MomieBarani dengan produk unggulannya yaitu BuTaRi (Bloeder Tape Durian) dan bolu terubuk, serta UMKM dodol, minuman segar Cola van Java dan jus buah Kawista. Dua UMKM ini termasuk usaha yang memasarkan produk dan olahan bahan khas kota Karawang dan mengenalkan oleh - oleh khas Karawang kepada masyarakat luas. Kedua mitra UMKM ini sudah mengetahui terkait pentingnya internet dan promosi di media internet, hanya saja manfaat dan efeknya belum terasa optimal.

\section{TARGET DAN LUARAN}

Mitra yang bekerjasama dalam pengabdian masyarakat ini adalah dua UMKM yang kreatif, inovatif dan mengangkat kekhasan Karawang, yaitu UMKM Dapur MomieBarani dengan produk unggulan BuTaRi (Bloeder Tape Durian) dan bolu terubuk serta UMKM dodol, minuman segar Cola van Java dan jus buah Kawista. Kedua UMKM ini sekarang aktif mempromosikan produknya dengan mengangkat branding oleh-oleh khas Karawang. Kedua mitra ini sudah memulai menerapkan digital marketing, tetapi hasilnya belum maksimal. Pendapatan UMKM ini sering diperoleh dari penjualan konvensional (offline), yaitu berasal dari keluarga, teman, komunitas atau jaringan yang dimiliki, dan para konsumen yang langsung membeli di toko atau outlet yang sudah ada.

Manajemen UMKM Dapur MomieBarani dilakukan sendiri oleh Ibu Ivy Fauzie dengan bantuan suaminya sebagai admin websitehttp://www.dapurmomiebarani.com.

Beberapa produk unggulan dari UMKM ini adalah BuTaRi (Bloeder Tape Durian), bolu terubuk, dan Lapijit (Lapis Legit Premium) yang dapat dilihat pada Gambar 2.1-3.

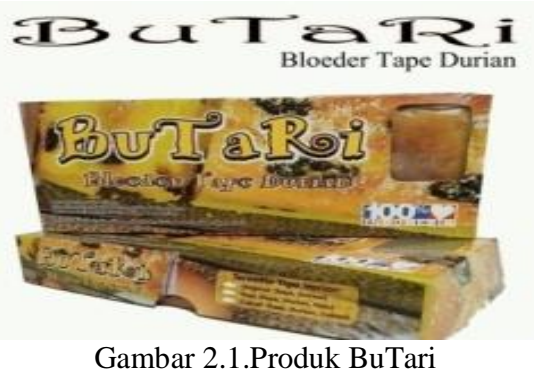

Bolu Turubuk Turubuk Khas Karawang

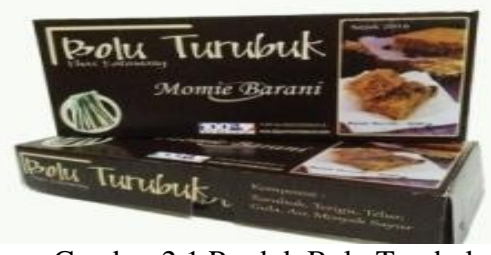

Gambar 2.1.Produk Bolu Terubuk

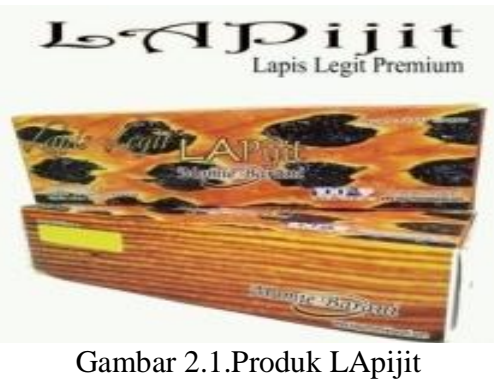


Selanjutnya, keunggulan UMKM yang dikelola oleh pasangan suami istri, Bapak Wawan Syarif dan Ibu Siti Maratusholiha adalah berfokus pada olahan buah Kawista. Produk unggulan yang dijual adalah dodol Kawista, minuman segar Cola van Java, dan jus buah Kawista yang langsung dijual di outlet yang sudah tersedia di daerah Telagasari, Karawang. Profil UMKM yang mengolah buah Kawista ini sudah beberapa kali dimuat di media cetak maupun media televisi karena unik dan mengangkat buat khas Karawang. Salah satu liputan media TV Berita Karawang dapat dilihat pada https://www.youtube.com/watch?v=LSDBpMSX40c. Adapun gambar produk unggulan UMKM ini dapat dilihat pada Gambar 2.2.

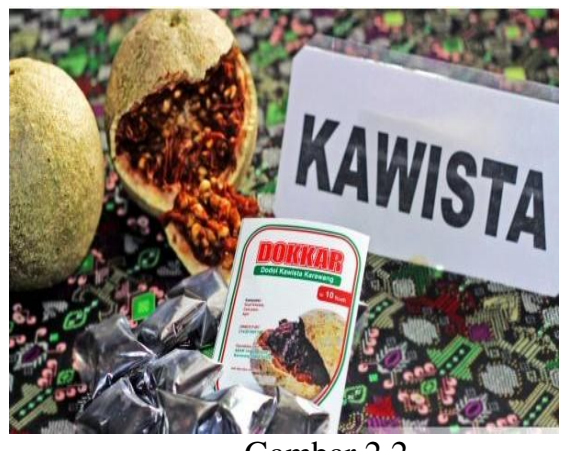

Gambar 2.2.

DOKKAR (Dodol Kawista) dan Cola Van Java

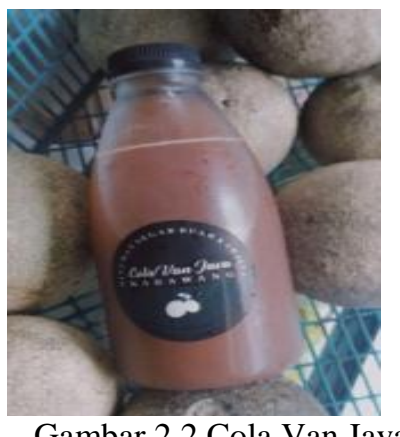

Gambar 2.2.Cola Van Java

UMKM Dapur MomieBarani bergerak di bidang kuliner dengan produk unggulan BuTaRi (Bloeder Tape Durian) dan bolu terubuk. Selain itu, UMKM ini juga melayani pesanan secara online berupa kue tart, cup cake, dan kue kering/basah. Informasi terkait produk, cara pemesanan, testimoni, facebook Fan Page, dan cara pemesanan dapat diakses pada website http://www.dapurmomiebarani.com. Tidak hanya melalui media website, sebenarnya UMKM ini sudah menggunakan marketplace bukalapak dengan akun https://www. bukalapak.com/u/momiebarani, tetapi lapak masih kosong, sekarang tidak aktif, dan belum adafeed back (0\%). Masalah yang dialami oleh UMKM ini adalah terkait digital marketing, bagaimana mengoptimalkan media internet untuk promosi atau marketing produk sehingga bisa memperluas jaringan dan memperkuat branding produk khas Karawang.

Buah Kawista merupakan buah khas Karawang yang sudah banyak dilupakan oleh masyarakat. Buah Kawista yang sudah matang biasanya langsung jatuh dari pohon sehingga lebih keluar aromanya. UMKM Dodol, minuman segar Cola van Java dan jus buah Kawista masih sering melakukan penjualan secara offline melalui toko atau outlet. Selain itu, UMKM ini juga memiliki banyak relasi sehingga banyak komunitas yang sering melakukan pemesanan, misalnya untuk acara rapat. Penjualan DOKKAR (dodol Karawang) sebelumnya menggunakan online marketplace di http://karawangbelanja.com/kuliner? product id=19, tetapi sayangnya tidak dikelola dengan baik sehingga belum memberi dampak positif yang signifikan. UMKM ini belum melakukan penjualan secara online secara mandiri, sehingga diperlukan pengenalan digital marketing agar penjualannya lebih optimal dan relasinya bertambah luas

Target dari pelaksanaan abdimas pada dua mitra UMKM di Kabupaten Karawang adalah meningkatkan kemampuan para pengusaha UMKM dalam pemanfaatan digital marketing, ditandai dengan adanya kenaikan jumlah pesanan produk dari media online. Selain itu, hasil pelaksanaan kegiatan pengabdian masyarakat ini dapat dipublikasikan melalui jurnal pengabdian masyarakat.

\section{METODE PELAKSANAAN}

Tahapan yang akan dilakukan terkait kegiatan ini adalah proses yang berkesinambungan dari mulai memperkenalkan atau sosialisasi pentingnya digital marketing, motivasi penggunaan fasilitas yang ada, menimbulkan keinginan untuk memanfaatkannya, menunjukkan hasil penggunaan, memberikan pelatihan, mendampingi pemanfaatannya sehingga para pengusaha UMKM dapat memanfaatkan fasilitas ini secara maksimal.

Adapun beberapa materi pelatihan digital marketing agar dapat dimanfaatkan dengan maksimal oleh semua peserta pelatihan dapat dilihat pada Tabel 3.1, meliputi materi pelatihan, pembahasan, durasi dan tujuan materi tersebut.

Tabel 3.1.Materi Pelatihan DigitalMarketing

\begin{tabular}{|l|l|l|l|l|}
\hline No & $\begin{array}{l}\text { Materi } \\
\text { pelatihan }\end{array}$ & Pembahasan & $\begin{array}{l}\text { Jumlah } \\
\text { jam }\end{array}$ & Tujuan \\
\hline 1 & $\begin{array}{l}\text { Pengenalan } \\
\text { Digital } \\
\text { marketing }\end{array}$ & $\begin{array}{l}\text { Definisi, } \\
\text { tujuan dan } \\
\text { manfaat, } \\
\text { digital } \\
\text { marketing } \\
\text { bagi UMKM }\end{array}$ & $\begin{array}{l}30 \\
\text { menit }\end{array}$ & $\begin{array}{l}\text { Peserta } \\
\text { program } \\
\text { paham akan } \\
\text { digital } \\
\text { marketing }\end{array}$ \\
\hline
\end{tabular}




\begin{tabular}{|c|c|c|c|c|}
\hline 2 & $\begin{array}{l}\text { Social } \\
\text { Media } \\
\text { Marketing } \\
\text { dan } e- \\
\text { commerce }\end{array}$ & $\begin{array}{l}\text { Berbagai } \\
\text { aplikasi } \\
\text { Social Media } \\
\text { Marketing } \\
\text { (Facebook, } \\
\text { instagram, } \\
\text { twitter, dst) } \\
\text { dan } e \text { - } \\
\text { commerce }\end{array}$ & $\begin{array}{l}30 \\
\text { menit }\end{array}$ & $\begin{array}{l}\text { Peserta } \\
\text { program } \\
\text { dapat } \\
\text { mengetahui } \\
\text { Social } \\
\text { Media } \\
\text { Marketing } \\
\text { dan } \text { - } \\
\text { commerce }\end{array}$ \\
\hline 3 & \begin{tabular}{|l} 
Content \\
Marketing
\end{tabular} & $\begin{array}{l}\text { - Isi atau } \\
\text { konten yang } \\
\text { menarik untuk } \\
\text { konsumen } \\
\text { - Foto produk, } \\
\text { Email } \\
\text { marketing, } \\
\text { Video } \\
\text { marketing }\end{array}$ & $\begin{array}{l}30 \\
\text { menit }\end{array}$ & $\begin{array}{l}\text { Peserta } \\
\text { program } \\
\text { dapat } \\
\text { menyiapkan } \\
\text { isi yang } \\
\text { akan } \\
\text { dipasarkan }\end{array}$ \\
\hline 4 & \begin{tabular}{|l} 
Manajemen \\
digital \\
marketing
\end{tabular} & $\begin{array}{l}\text { Memanajeme } \\
\text { ndigital } \\
\text { marketingden } \\
\text { agn jadwal } \\
\text { posting isi } \\
\text { atau konten } \\
\text { serta feedback }\end{array}$ & $\begin{array}{l}30 \\
\text { menit }\end{array}$ & $\begin{array}{l}\text { Peserta } \\
\text { program } \\
\text { dapat } \\
\text { memanajem } \\
\text { endigital } \\
\text { marketing } \\
\text { yang sudah } \\
\text { dilakukan }\end{array}$ \\
\hline 5 & $\begin{array}{l}\text { FGD digital } \\
\text { marketing }\end{array}$ & $\begin{array}{l}\text { Forum Group } \\
\text { Discussion } \\
\text { (FGD) saat } \\
\text { pelatihan } \\
\text { pemanfaatan } \\
\text { digital } \\
\text { marketing }\end{array}$ & $2 \mathrm{jam}$ & $\begin{array}{l}\text { Peserta } \\
\text { program } \\
\text { dapat } \\
\text { berbagi } \\
\text { setelah } \\
\text { pelatihan } \\
\text { selesai }\end{array}$ \\
\hline 6 & $\begin{array}{l}\text { Evaluasi } \\
\text { pelatihan } \\
\text { digital } \\
\text { marketing }\end{array}$ & $\begin{array}{l}\text { Mengevaluasi } \\
\text { hasil dari } \\
\text { pelatihan } \\
\text { yang sudah } \\
\text { dilakukan }\end{array}$ & $2 \mathrm{jam}$ & $\begin{array}{l}\text { Peserta } \\
\text { program } \\
\text { dapat } \\
\text { berbagi } \\
\text { setelah } \\
\text { pelatihan } \\
\text { dan } \\
\text { mengevalua } \\
\text { si kegiatan }\end{array}$ \\
\hline
\end{tabular}

IV. HASIL DAN PEMBAHASAN

Hasil kegiatan pengabdian kepada masyarakat terbagi menjadi beberapa tahapan, yaitu :

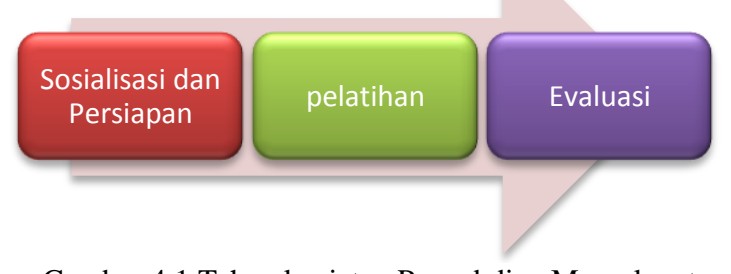

Gambar 4.1 Tahap kegiatan Pengabdian Masyakarat

1. Sosialisasi dan persiapan

Sosialiasi dan persiapan dilakukan untuk menetapkan jadwal pelatihan digital marketing selama 1 bulan mulai 6 Agustus sampai 6 September 2018. Adapun sosialisasi dilakukan dengan mengunjungi dua mitra sebagai mitra pengabdian masyarakat, yaitu mengunjungi UMKM DOKKAR dan UMKM Dapur MomieBarani. Target peserta workshop UMKM adalah 30 orang. Selain sosialisasi, tahap persiapan juga dilakukan dengan membentuk panitia pelaksana kegiatan, yaitu kolaborasi dengan Relawan TIK Muda Karawang.

Pada hari Kamis, tanggal 30 Agustus 2018 kunjungan ke UMKM DOKKAR untuk membahas persiapan kegiatan pelatihan digital marketing. Selanjutnya pada hari Sabtu, tanggal 2 Oktober 2018 kunjungan ke UMKM Mommie Barani untuk diskusi terkait materi dan daftar peserta UMKM yang akan hadir.

\section{Pelatihan dan Pendampingan}

Pelatihan dan pendampingan dilakukan pada hari Sabtu, 23 September 2018 di ruang kelas fakultas Agama Islam, Universitas Singaperbangsa. Panitia pelaksan kegiatan pengabdian ini bekerjasama dengan Relawan Teknologi Informasi dan Komunikasi (TIK) Muda Kabupaten Karawang. Pelaksanaan pelatihan digital marketing mengundang pemateri dari pihak Tokopedia untuk menjelaskan bagaimana strategi dan langkah untuk memasarkan produk melalui digital marketing. Peserta yang hadir sebanyak 27 orang yang mewakili kedua mitra UMKM mitra kegiatan abdimas ini. Foto bersama peserta pelatihan dan panitia pelaksana pelatihan digital marketing dapat dilihat pada Gambar 4.1.

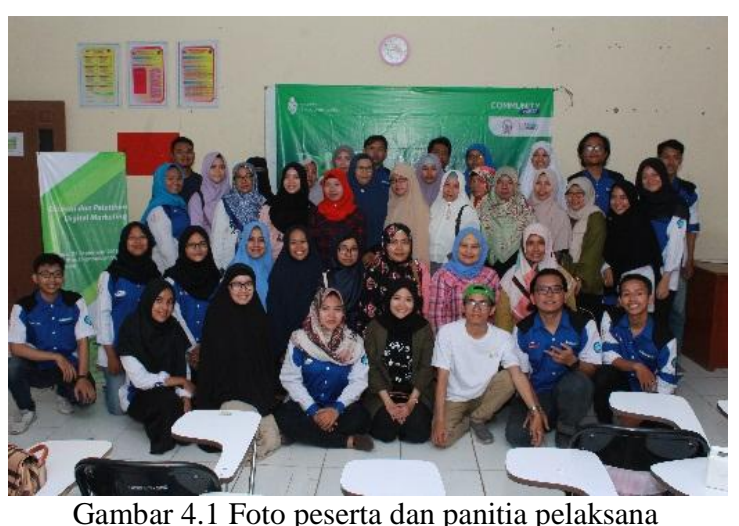

Gambar 4.1 Foto peserta dan panitia pelaksana

Materi yang disampaikan saat pelatihan digital marketing fokus pada e-commerce yang berupa market place, yaitu tokopedia. Pihak manager Tokopedia menjelaskan kepada peserta mengenai apa itu $e$-commerce, market place, sampai pada cara melakukan transaksi jual beli. Berikut ini salah satu 
dokumentasi saat pelatihan digital marketing pada gambar 4.2.

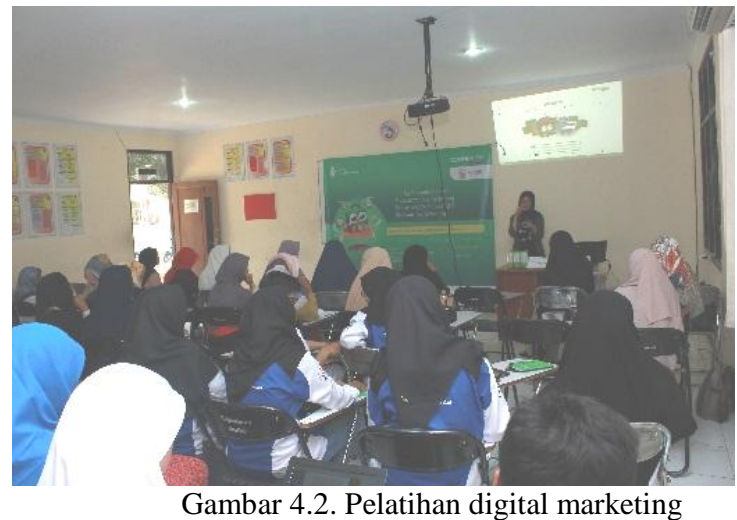

Kegiatan pelatihan digital marketing diikuti oleh 27 orang dari jaringan dan komunitas dua mitra, yaitu UMKM DOKKAR dan UMKM Dapur MomieBarani. Kegiatan ini dimulai dari pukul 08.30 WIB sampai dengan 15.00 WIB. Materi yang disampaikan meliputi pengenalan digital marketing, social media marketing dan e-commerce, content marketing dan manajemen digital marketing. Pelatihan digital marketing diisi oleh Manager dari Tokopedia, didukung oleh Top Community di Karawang. Hal ini bermanfaat untuk para peserta pelatihan, karena bisa bergabung dan melakukan knowledge sharing bersama komunitas UMKM di Karawang terkait memulai berjualan di marketplace Tokopedia.

Pendampingan dari pihak panitia dan pemateri kepada para peserta pelatihan dilakukan selama pelatihan berlangsung. Pemateri memberikan arahan dan petunjuk teknis apa yang harus dilakukan para peserta untuk mempraktikkan beberapa hal untuk keperluan transaksi jual beli onlie di marketplace. Hal ini dapat dilihat pada Gambar 4.3.

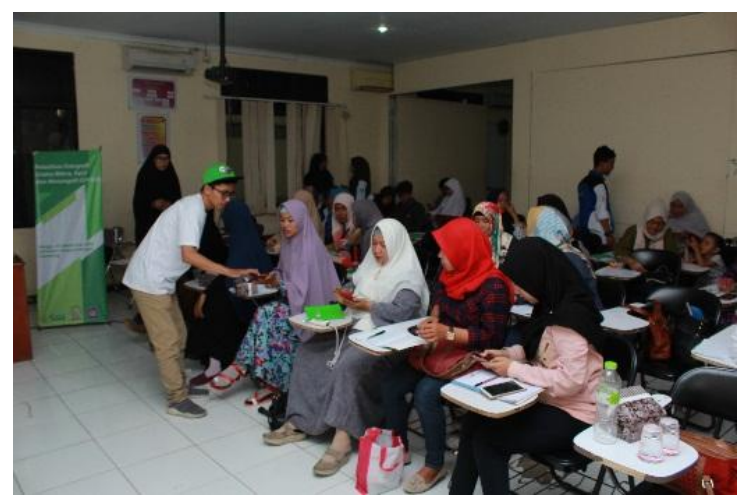

Gambar 4.3. Pendampingan selama pelatihan
3. Evaluasi

Evaluasi dilakukan setelah pelatihan pemanfaatan digital marketing selesai melalui Google Form yang disebarkan melalui group WhatsApp peserta pelatihan digital marketing. Form bisa diakses melalui alamat https://goo.gl/2NvgPZ .

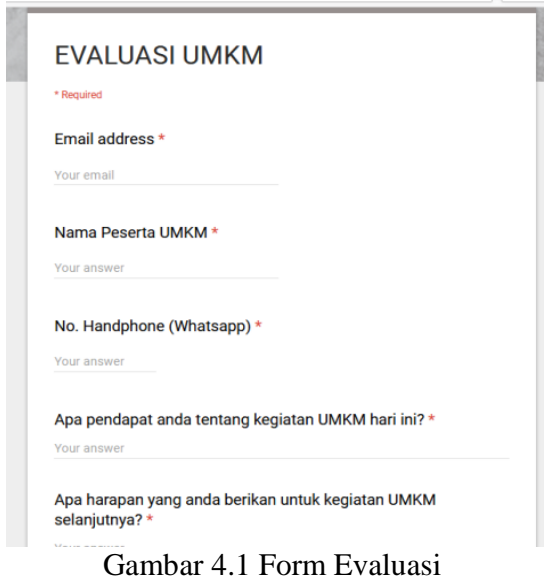

\section{KESIMPULAN}

Kegiatan pengabdian pelatihan digital marketing untuk UMKM di Kabupaten Karawang yang diikuti oleh dua komunitas UMKM mitra berjalan denganbaik dan lancar. Kesimpulan kegiatan pengabdian masyarakat ini adalah sebagai berikut :

1. Pelatihan digital marketing yang berisi terkait pengenalan digital marketing, social media marketing dan e-commerce, content marketing dan manajemen digital marketing menjadi sarana edukasi dan menambah wawasan terkait digital marketing kepada dua mitra UMKM.

2.Pelatihan menerapkan strategi digital marketing kepada dua mitra UMKM telah disampaikan melalui workshop dan praktik selama kegiatan berlangsung. 3.Evaluasi pelatihan digital marketing yang telah dilaksanakan kepada dua mitra UMKM melalui Google Form meliputi materi yang disampaikan, fasilitas pelatihan dan penambahan wawasan serta skill mengenai digital marketing.

\section{UCAPAN TERIMA KASIH}

Ucapan terima kasih disampaikan kepada Lembaga Penelitian dan Pengabdian Masyarakat LPPM Universitas Singaeperbangsa Karawang yang telag mendukung dan memberikan dana untuk melaksanakan pengabdian masyarakat ini.

\section{DAFTAR PUSTAKA}

[1] Rahmana, Arief. 2009. Peranan Teknologi Informasi Dalam Peningkatan Daya Saing Usaha Kecil Menengah.. Seminar Nasional Aplikasi Teknologi Informasi 2009 (SNATI 2009). Yogyakarta, 20 Juni 2009. Pp (B11-15) 
Jurnal Pengabdian Masyarakat J-DINAMIKA, Vol. 4, No. 2, Desember 2019,

P-ISSN : 2503-1031, E-ISSN: 2503-1112 